\title{
CURrículo de Autores
}

\section{Anargelis Chacín}

Ingeniero de Petróleo, egresado de la Universidad del Zulia Núcleo Costa Oriental del Lago Venezuela. Maestría en Gerencia de Empresas Mención Gerencia de Operaciones. Universidad del Zulia Núcleo Costa Oriental del Lago.

\section{Boreidy Jiménez}

Licenciada en Administración. Maestría en Gerencia de Empresas. Mención: Gerencia de Operaciones. Universidad del Zulia Núcleo Costa Oriental del Lago.

\section{Danny Garcia}

Ingeniero de Petróleo, egresado del Politécnico Santiago Mariño. Maestría en Gerencia de Empresas, mención Operaciones. Universidad del Zulia.

\section{Nelsy Caridad}

T.S.U. en Administración, Mención Informática Colegio Monseñor de Talavera, Cabimas, Edo. Zulia, Venezuela. Licenciada en Administración, Mención Gerencia Industrial Universidad Experimental Rafael María Baralt, Cabimas, Edo. Zulia, Venezuela. Magister en Gerencia Financiera L.U.Z. Cabimas, Edo. Zulia, Venezuela. 